\title{
Strategies for Overcoming Barriers to Improving Safety in Small Construction Organisations
}

\author{
Sunindijo, R.Y. ${ }^{1}$
}

\begin{abstract}
The majority of organisations in the construction industry are small organisations, how ever their safety performance is still far behind their larger counterparts. Therefore, it is important to focus on improving safety performance of small organisations so that the overall industry performance may be improved. Using a questionnaire survey, this research collected data from construction organisations based in New South Wales, Australia. Data analysis results have identified key barriers faced by small organisations when implementing safety. These barriers include the use of lowest bid price to evaluate tender submissions, lack of safety commitment from construction clients, and fierce competition. The analysis results have also revealed potential strategies for overcoming the barriers, such as including safety as an indicator in tender evaluation, more effective safety regulation enforcement by inspection and linking safety performance with insurance premium and licencing system, and subsidising safety training for small organisations. Improving safety performance in this sector cannot be done in isolation. The government, clients, and large organisations have important roles to play to change the norms and culture in the industry so that small organisations are supported in their effort to improve their safety performance.
\end{abstract}

Keywords: Australia; barriers; construction industry; safety; small organisations; strategies.

\section{Introduction}

Generally, efforts to improve safety in the construction industry have been focused on large organisations [1]. These efforts have shown positive results. Today these market leaders have developed robust safety management systems and their performance is significantly better than the national average. A case study in a large construction organisation in Australia found that the percentages of safety investments against project contract sums in the organisation are considerably higher than the industry average. This not only resulted in better safety performance, but the extra investment also generated economic benefits in the form of the saving that the organisation obtained from reducing the number of accidents [2].

This improvement among large organisations is certainly welcomed. However, the construction industry is typically dominated by small organisations. In Australia, more than 98\% of construction organisations are small businesses, employing fewer than 20 people [3]. Arewa and Farrell [4] found that small organisations constitute more than $90 \%$ of all businesses and account for $83.7 \%$ of employment and $67.4 \%$ of turnover generation in the construction industry. Despite their substantial contributions to the construction industry, small organisations tend to have poorer safety performance than their larger

${ }^{1}$ Faculty of Built Environment, UNSW Australia, Sydney, NSW 2052 AUSTRALIA. Email: r.sunindijo@unsw.edu.au counterparts [5]. For example, in Europe small organisations account for $67 \%$ of employment in all sectors, but are responsible for $82 \%$ of occupational injuries [6].

Figure 1 illustrates the evolution of safety culture of a construction organisation. As the safety culture improves, there is a correlation with the reduction of incidents and injuries. At the start of each stage, a reduction in incidents and injuries is achieved, followed by a plateauing of performance before moving into the next stage [7]. The traditional stage is reactive, where hazards are dealt with as they arise and there is a strong emphasis on discipline, such as enforcing the use of personal protective equipment. The transitional stage is more proactive where safety management processes are used to identify hazards before activities begin and to establish procedures to mitigate the hazards. The innovative stage integrates safety into all decision making, while every attempt is made to eliminate health and safety risks using technological solutions $[8,9]$.

Figure 2 depicts a simplistic timeline which shows how medium and small organisations follow large organisations in the development of safety culture. It is conceptualised that currently large construction organisations in developed nations are in the innovative stage, medium organisations have begun to enter the transitional stage, while small organisations are still in the traditional stage [8]. 


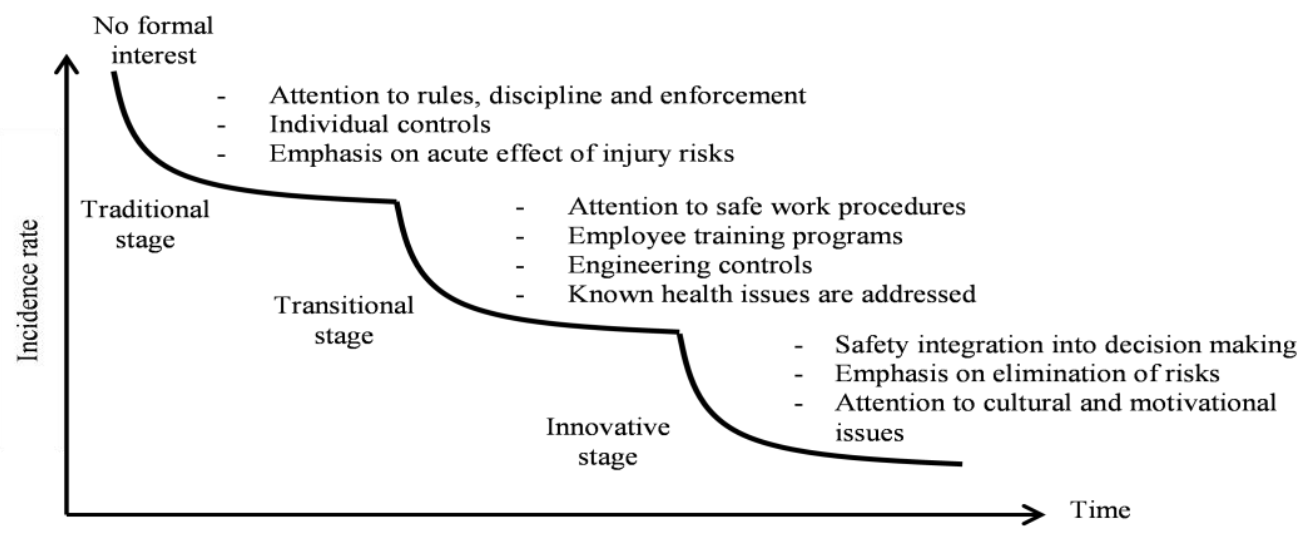

Figure 1. The Evolution of Safety Culture (adapted from Pybus [7] in Lingard and Rowlinson [9])

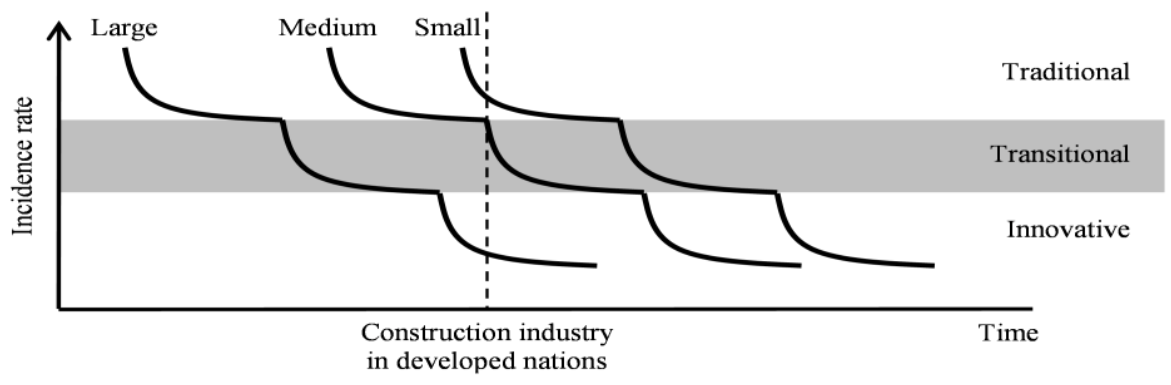

Figure 2. Stages of Safety Culture Varying with Organisation Size (adapted from Finneran and Gibb [8])

In less developed countries, the line should be shifted to the left to reflect their current safety culture. It is argued, therefore, that the focus of safety effort in less developed countries should be on large construction organisations, while in developed countries more attention should be given to small organisations.

Despite the need to improve safety in small organisations, research on this area is still relatively limited [10] and scattered between different disciplines and institutions [11]. The research presented in this paper is an initial step to improve safety in small organisations in the Australian construction industry. As in any research effort, determining research problems is an important first step. Therefore, this research aims to identify key barriers, i.e., problems, that constrain these organisations from improving their safety performance. Furthermore, this research also aims to identify strategies or interventions that can overcome the barriers and bring about improvements.

\section{Research on Safety in Small Organisations}

A search of literature was conducted to find articles and research studies on safety in small organisations published from 1991 to 2014. Using a number of search engines, including Google Scholar, American Society of Civil Engineers, Science Direct, Emerald Insight, and Taylor \& Francis, 27 keywords were keyed in to find relevant publications. The search found 125 research papers and three books (including one edited book), which represent a wide range of industries, including agriculture, chemical, construction, manufacturing, mining, and transporttation. Many of them do not address a specific industry, but cover small organisations in general. Table 1 summarises some characteristics of these publications.

As presented in Table 1, the number of research on safety in small organisations has increased steadily over the years. There are only two relevant publications from 1991-95, but the number increases to 59 from 2011-14. This indicates that researchers have begun to realise the importance of focusing on small organisations to improve safety at work.

The publications were also categorised based on where their data were collected. When this is not explicitly informed, the affiliation of the author(s) is used to determine the location of the research. Europe seems to be leading the way by contributing more than $40 \%$ of the research publications. 
Table 1. Publications on Safety in Small Organisations

\begin{tabular}{llcc}
\hline \multicolumn{1}{c}{ Factor } & \multicolumn{1}{c}{ Sub-factor } & Number & Percentage \\
\hline Year & $2011-14$ & 59 & 46.09 \\
published & $2006-10$ & 37 & 28.91 \\
& $2001-05$ & 16 & 12.50 \\
& $1996-2000$ & 14 & 10.94 \\
& $1991-95$ & 2 & 1.56 \\
\hline Research & Africa & 10 & 7.81 \\
location & Asia & 26 & 20.31 \\
& Australasia & 53 & 15.63 \\
& Europe & 16 & 12.41 \\
& North America & 1 & 0.78 \\
& South America & 2 & 1.56 \\
\hline Mixed regions & 39 & 25.32 \\
mesearch & Review or conceptual & 30 & 19.48 \\
& Questionnaire & & \\
& Interview and focus & 42 & 27.27 \\
& group & 10 & 6.49 \\
& Case study & & \\
& Action research and & 10 & 6.49 \\
& experiment & & \\
& Secondary data & 18 & 11.69 \\
& analysis & & \\
& Others, including & & 3.25 \\
\hline & ethnography and & & \\
& observation & &
\end{tabular}

One of the efforts to improve safety in Europe is the formation of the European Agency for Safety and Health at Work (EU-OSHA) in 1994. EU-OSHA is the main organisation in the European Union which is responsible for providing their stakeholders with the technical, scientific, and economic information to make Europe a safer, healthier, and more productive place to work. The organisation acknowledges that work-related accidents in small organisations are pressing issues that should be concentrated on [12].

Lastly, the publications were categorised based on their research methods. The total number in this category is higher than the total number of the publications (128) because some research adopted more than one research method. Questionnaire survey is, surprisingly, not the dominant research method. This is in contrast to the research conducted by Zou et al. [13] who found that questionnaire survey is the dominant research method in construction safety research. It is possible that research on safety in small organisations is relatively new, so that researchers need to use an inductive approach to tackle the topic. The inductive approach promotes the use of qualitative research methods, such as interviews and case studies, to form theories based on the conditions in practice.

\section{Barriers to Implementing Safety in Small Organisations}

Each publication found from the literature search identifies and, into a certain extent, discusses the barriers to implementing safety in small organisations. These barriers can be classified into the following factors:
- Client demands. Due to the competitive nature of the construction industry, economic survival and gaining of contracts are often prioritised over safety considerations [14]. The intense competition also causes the clients to 'dictate' the construction industry. They have high bargaining powers because more players, i.e., small organisations, are competing for the same market [15]. Therefore, clients use competitive tendering as a feasible procurement method to assure that a job is carried out at the lowest possible cost. This method, however, may worsen safety risks because economic pressures and competitions penalise those organisations that try to do the right thing due to their higher tender prices [16, 17]. The clients pay more attention on getting the job done rather than worker safety because they perceive small organisations as disposable and replaceable items [17]. As a result, small organisations prioritise on maintaining good relations with their clients over safety $[1,18]$.

- Negative perceptions towards safety. The owners of small organisations perceive that safety regulations are too excessive and complex, preventing them from implementing those regulations effecttively [19]. They also consider safety regulations and demands to improving safety as a financial burden which is too heavy and unrealistic [11]. Unlike large organisations, small organisations are unable to distribute their compliance costs over a number of products, markets, or plants [20]. Health and Safety Executive [21] found that although large organisations spend more on safety than small organisations, when calculated per employee, small organisations spend seven times more than large organisations. Although they understand that poor safety has negative impacts on the financial performance of their organisations, they perceive that the costs of compliance with certain aspects of regulations are too high in comparison to the perceived benefits and are detrimental to their survival [20, $22]$.

- Lack of safety knowledge and inadequate safety training. The owners and managers of small organisation do not have sufficient safety knowledge to implement safety measures and to appreciate the importance of safety [23]. They perceive that their work is repetitive and simple, thus they tend to underestimate safety risks and believe that those risks are part of the job [24]. This condition is made worse by the lack of safety training because it is seen as expensive and unnecessary. At the same time, compulsory safety training is considered as inadequate or ineffective to gain the required safety knowledge and to develop positive safety attitudes [17, 25]. 
- Poor safety culture. All the previous barriers eventually result in poor safety culture among small organisations. Owners and managers in these organisations do not consider safety as a priority because they are already inundated by other more 'urgent' issues to meet the requirements of their clients. Compliance to regulations is their primary approach to implementing safety and they perceive that implementing higher safety standards is pointless due to implementtation costs and additional resources required [26]. They also often place the control mechanism of safety risks to their workers and blame them when accidents occur [27]. This lack of management commitment worsens the already poor safety attitudes of the workforce in small organisations [1].

\section{Strategies for Overcoming the Barriers}

Besides highlighting the barriers, the existing literature also proposes strategies for improving safety in small organisations. These strategies are summarised below. They are discussed in more detail in the discussion section.

- Client safety roles. Clients are in the best position to drive the cultural change needed to bring about safety improvements as they make key decisions that can accommodate or constrain safety implementation [28]. They should acknowledge that safety complements quality and schedule, which, ultimately, will lead to a reduction in construction costs. Although small clients may not have the resources and expertise to undertake comprehensive safety interventions, nothing precludes them from enquiring about a contractor's safety performance and making reference to safety during the course of a project [29].

- Safety training. The costs of safety training and compliance are a major barrier for small organisations due to their limited financial capacity and economic pressures caused by the norms and characteristics of the construction industry. Therefore, free safety training courses or training incentives should be provided to small organisations that are qualified to receive such supports. It is also important to assess the effectiveness of existing safety training programs because this aspect tends to be neglected in practice.

- Enforcement of safety regulations. The government should find a way to effectively monitor and enforce safety regulations [11]. Without proper enforcement, small organisations that try to implement safety would be at a disadvantage over those that cut corners [16]. The government should also come up with incentive programs that encourage small organisations to focus on safety, for example, by linking safety performance with insurance premium, taxes, and licensing systems in the industry.

\section{Research Methods}

A three-section self-assessed questionnaire was developed and used for collecting data. The first section is about the profile of the respondents. The second section consists of 13 barriers to safety improvement among small organisations and the third section consists of 13 items representing strategies to improve safety performance among small organisations. The items were drawn from the literature review discussed in the previous sections. The second and third sections use a five-point Likert scale format ranging from 'strongly disagree' to 'strongly agree'.

Due to the large number of small construction organisations, the scope of the research is currently limited to New South Wales (NSW), Australia. A list of construction organisations email addresses was compiled from the yellow pages. The questionnaire was then distributed via emails to 838 construction companies in the NSW region. Two reminders were sent to each company in the following two weeks.

\section{Analysis and Discussion}

Seventy-two valid responses were received, representing an $8.6 \%$ response rate. Twelve respondents (16.7\%) are females and 60 respondents (83.3\%) are males. Forty-six respondents $(63.9 \%)$ worked in organisations that had fewer than 20 employees, 16 respondents $(22.2 \%)$ worked in organisations that had 20-99 employees, and 10 respondents worked in organisations that had 100 or more employees. Thirty-nine respondents (54.2\%) were business owners or self-employed. On average, the respondents had more than 23 years of work experience in the construction industry. Furthermore, the first section of the questionnaire also includes four additional questions and the results are presented in Table 2. Based on items 1 and 2, generally the respondents were satisfied with current safety performance in their organisations. They, however, recognised that safety performance in small construction organisations still needs to be improved (item 3) and they also believed that it is not impossible to improve this performance (item 4 ).

Table 2. Perceptions on Current Safety Performance

\begin{tabular}{clc}
\hline No & Item & Mean \\
\hline 1 & $\begin{array}{l}\text { I am satisfied with safety performance in my } \\
\text { organisation }\end{array}$ & 4.03 \\
2 & $\begin{array}{l}\text { I consider safety as equally important as } \\
\text { other project objectives }\end{array}$ \\
3 & $\begin{array}{l}\text { Safety performance among small companies } \\
\text { in the construction industry needs to be }\end{array}$ \\
$\quad \begin{array}{l}\text { improved } \\
4\end{array}$ & $\begin{array}{l}\text { Due to the nature of the construction } \\
\text { industry, NOT much can be done to improve } \\
\text { safety among small companies }\end{array}$ & 2.43 \\
\hline
\end{tabular}

Notes:

For means, $1=$ strongly disagree and $5=$ strongly agree 
The barriers to safety improvement are presented in Table 3, while the strategies for improvements are presented in Table 4. The items have been ranked from the highest to the lowest based on the respondents' responses. A one-sample t-test was conducted to find out which barriers and strategies were deemed relevant and which ones were not. The test value was a score of 3.00 , meaning neutral. The significance values of this test are presented in the last columns on Tables 3 and 4.

Table 3. Barriers to Improve Safety Performance in Small Organisations.

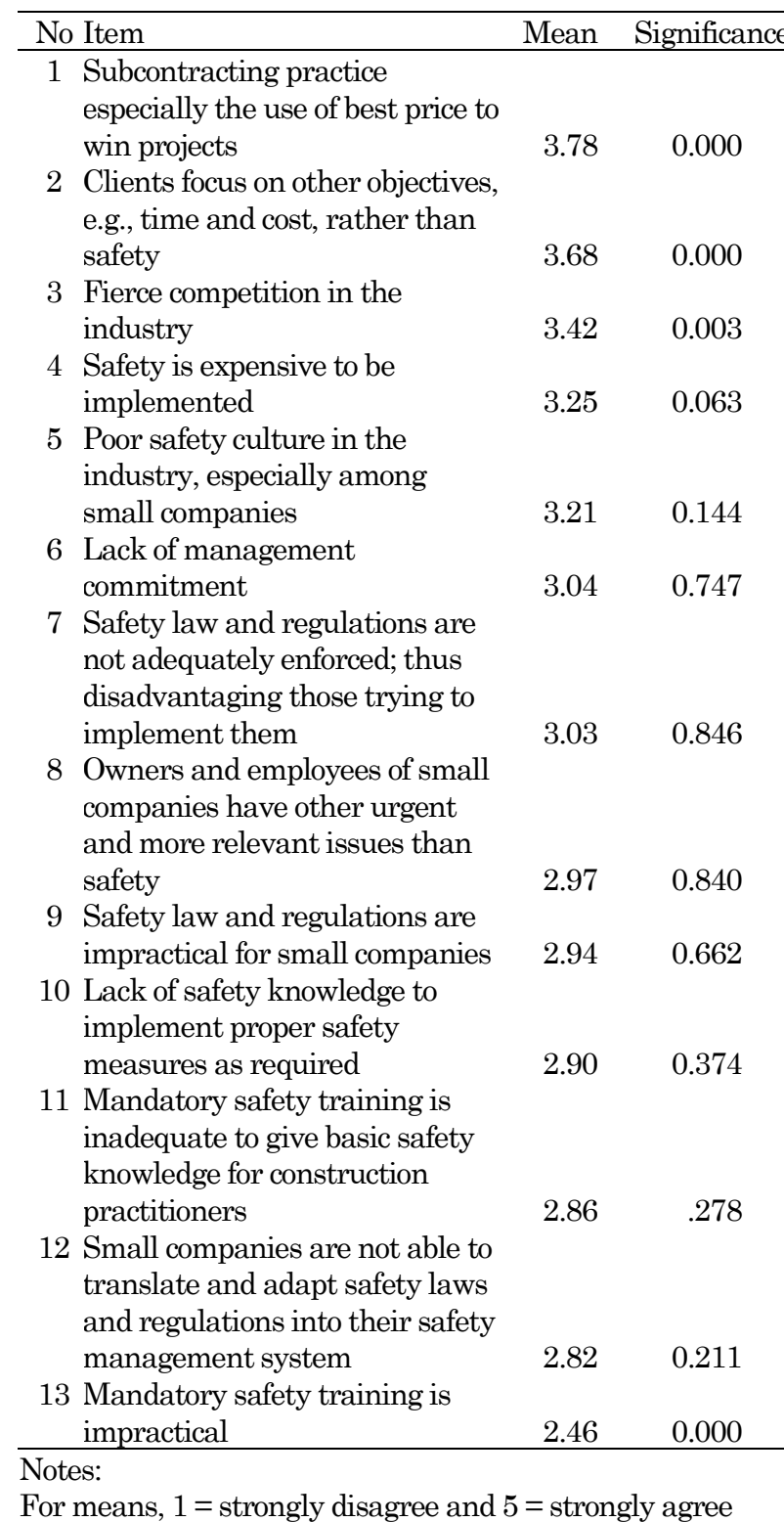

\section{Barriers to Improve Safety}

As presented in Table 3, the significant values of the top three barriers are less than 0.05 , indicating that the respondents perceived that these barriers are particularly important. The topmost barrier is the subcontracting practice that uses the lowest price as the main criterion to win projects. Research has shown that subcontracting has negative impacts on safety performance in the construction industry. It is difficult to monitor and enforce safety on construction sites that have multiple subcontractors, thus increasing the risk of paper compliance escaping undetected [30]. The attempts to minimise costs worsen this condition and have been found to cause breaches of safety standards and regulations [17].

Table 4. Strategies to Improve Safety Performance among Small Organisations

\begin{tabular}{|c|c|c|c|}
\hline No & Item & Mean & Significance \\
\hline 1 & $\begin{array}{l}\text { Clients should consider safety } \\
\text { as one of the project success } \\
\text { factors }\end{array}$ & 4.13 & 0.000 \\
\hline 2 & $\begin{array}{l}\text { Safety should be one of the } \\
\text { criteria in tendering }\end{array}$ & 4.07 & 0.000 \\
\hline 3 & $\begin{array}{l}\text { Government should subsidise } \\
\text { safety training for small } \\
\text { companies that meet } \\
\text { requirements }\end{array}$ & 4.04 & 0.000 \\
\hline 4 & $\begin{array}{l}\text { Safety performance and } \\
\text { compliance should be linked to } \\
\text { insurance premium }\end{array}$ & 3.67 & 0.000 \\
\hline 5 & $\begin{array}{l}\text { Safety performance and } \\
\text { compliance should be linked to } \\
\text { the licencing system of } \\
\text { construction companies }\end{array}$ & 3.67 & 0.000 \\
\hline 6 & $\begin{array}{l}\text { Government should enforce } \\
\text { safety law and regulations } \\
\text { effectively }\end{array}$ & 3.57 & 0.000 \\
\hline 7 & $\begin{array}{l}\text { Mandatory safety training } \\
\text { should be more thorough and } \\
\text { harder to pass }\end{array}$ & 3.41 & 0.002 \\
\hline 8 & $\begin{array}{l}\text { Small companies should form a } \\
\text { "safety responsible group" to } \\
\text { share safety resources and to } \\
\text { ensure that the each group } \\
\text { member meets safety } \\
\text { requirements }\end{array}$ & 3.29 & 0.022 \\
\hline 9 & $\begin{array}{l}\text { Obtaining and renewing } \\
\text { builder's and construction- } \\
\text { related licences should be made } \\
\text { tougher }\end{array}$ & 3.14 & 0.388 \\
\hline 10 & $\begin{array}{l}\text { Government should explicitly } \\
\text { tell small companies what to do } \\
\text { to implement safety }\end{array}$ & 3.03 & 0.835 \\
\hline 11 & $\begin{array}{l}\text { Safety law and regulations } \\
\text { should be less prescriptive to } \\
\text { allow small companies to self- } \\
\text { regulate safety }\end{array}$ & 2.97 & 0.916 \\
\hline 12 & $\begin{array}{l}\text { Harsher punishments or } \\
\text { consequences to small } \\
\text { companies that violate safety } \\
\text { regulations }\end{array}$ & 2.78 & 0.114 \\
\hline 13 & $\begin{array}{l}\text { Worker unions should pressure } \\
\text { small companies to focus on } \\
\text { safety }\end{array}$ & 1.82 & 0.000 \\
\hline
\end{tabular}
Notes:

For means, $1=$ strongly disagree and $5=$ strongly agree

For example, the majority of fatal victims in the Singaporean construction industry were employed by subcontractors. Even if the main contractors have 
good safety management systems in place, their subcontractors may not be adequately integrated into the systems. These subcontractors are also employed despite their unsafe practices because they offer lower prices that help the main contractors secure contracts and make profits [31]. A study in the US found that the demand for cheap construction services and the practice of bidding for jobs, force smaller subcontractors to cut corners whenever they can. These include neglecting safety and other illegal practices [18].

Today, large organisations have the opportunity to mark-up their prices depending on project characteristics, such as degree of difficulty, contract size, and degree of safety. Smaller organisations, however, are more concerned about their own financial performance and the necessity to maintain a viable business. These small organisations also tend to be involved in construction projects as subcontractors. Coupled with the lowest price mentality, small organisations are under constant pressure to reduce their prices, which could have negative impacts on their safety performance [32,33].

The second barrier is the characteristics of clients in the construction industry that still focus on objecttives other than safety. Clients of small organisations tend to focus on getting the job done as quickly and as cheap as possible. They also consider small organisations to be disposable because they have the ability to choose among many service providers. This forces small organisations to keep their clients happy by, if necessary, neglecting safety and conducting other illegal practices [1]. For example, there was a case where a small organisation did not implement proper safety measures, but still getting the job because their cost was cheaper than another organisation that included safety in their work methods [16].

The third barrier is the fierce competition in the industry. This barrier is essentially related to the previous two barriers. Many clients in the construction industry still use lowest price as the main indicator in evaluating tender submissions. They also still focus on traditional project objectives, like time and cost rather than safety, as indicators of project success. This client-dominated industry together with the large number of small organisations worsen the competition in the industry, compelling small organisations to reduce their operational costs by any means necessary to remain competitive.

Another matter worth to be mentioned is that item 13 of Table 3 "mandatory safety training is impractical" also has a significant value. This means that this item should not be considered as a barrier because its mean is significantly lower than 3 .

\section{Strategies for Overcoming the Barriers}

Table 4 shows potential strategies that can be used to address the barriers identified previously. The top eight strategies have significant values less than 0.05 , indicating that they were perceived as important. The first seven strategies require the collaboration of clients and the government or regulatory bodies in their implementation. This is understandable because the top barriers are external barriers in which small organisations have limited to no control over them. Therefore, strategies to remove the barriers should not only focus on activities that can and should be done by small organisations, but also on the norms and culture of the construction industry. As such, the government, large organisations, and clients should be involved in the transformation process; otherwise it would be impossible to address those barriers effectively.

As mentioned earlier, clients are in the best position to drive the cultural change needed to bring about safety improvements as they are the initiators of project development. They make key decisions concerning budget, project objectives, timelines, and performance criteria, which can support or constrain safety implementation [28]. A research study found that clients of small organisations in the Australian construction industry can contribute to improving safety performance by performing six client safety roles: (1) participate in site-based safety program; (2) review and analyse safety data; (3) appoint safety team; (4) select safe contractors; (5) specify how safety is to be addressed in tenders; and (6) perform regular checks on plant/equipment. The government and large organisations who are also construction project clients should proactively take the lead in performing these roles [34].

There must be stronger enforcement of safety regulations in practice. Currently, the safety inspectorate is not able to effectively monitor and enforce safety regulations due to the large number of small organisations [11]. Without proper control, small organisations that put some effort to be ethical and follow the regulations are always at a disadvantage because their operational costs and tender prices are likely to be more expensive than those that cut corners. As a result, there is no incentive for them to focus on safety because safety has become detrimental to their business survival. Safety inspectors also often take inconsistent approach depending on their moods. This further causes a deep sense of insecurity and dissatisfaction among small organisations which feeds into negative perceptions towards safety regulations [17]. The following are what the government and professional bodies can do to improve compliance: 
- Increase spot checks or random site visits by the safety inspectorate. There is a tendency that inspectors prefer to visit large projects. Although this is understandable, smaller projects should not be completely ignored. Furthermore, these random visits should not merely focus on finding the wrongs, but should give small organisations opportunities to improve their safety practices.

- Link safety performance and compliance to the licensing system of construction organisations.

- Tax reduction and other incentives for those who consistently demonstrate good safety performance.

Larger organisations should also collaborate with the government and small organisations to develop practical checklists and tools to measure safety performance on sites periodically. They should take the lead in demonstrating their commitment towards safety by rigorously monitoring safety implementation, rewarding good safety performance, mentoring and supporting their subcontractors so that they improve their safety performance, and punishing serious breaches of safety regulations. It is also important for large organisations to allow for extra costs in relation to safety when assessing tenders and awarding contracts to subcontractors. In this case, safety should be one of the criteria during the procurement process. Likewise, public projects should also include safety as one of the criteria in procuring contractors.

The cost of safety training and compliance is a major barrier for small organisations. Therefore, it is recommended that free safety training courses should be provided to these organisations. Specific criteria need to be established to determine those small organisations that are qualified to get this benefit. It is also important to assess the effectiveness of existing safety training programs because this aspect tends to be neglected. Kirkpatrick and Kirkpatrick [35] developed a four-part process to evaluate the effectiveness of training programs which can also be applied in the context of safety training. The following is the four-part process: (1) Reaction - a satisfaction survey to measure how trainees feel about the various aspects of a training program including the topic, trainer, training approach, and so forth; (2) learning - measuring the knowledge acquired, skills developed, or attitudes changed as a result of the training; (3) behaviour measuring the extent to which trainees change their on-the-job behaviour as a result of training; and (4) results - measurement of the long-term results that occur due to training, such as safety culture development, job satisfaction, client satisfaction, and profits.
Another strategy is that small organisations can collaborate and form a "safety responsible group" where the members can share resources related to safety. The group also serves as a control mechanism to ensure that each member meets safety requirements. By sharing their resources, the disadvantage faced by small organisations in terms of the economy of scale can be lessened.

Lastly, the respondents did not consider item 13 of Table 4 "worker unions should pressure small companies to focus on safety" as a feasible strategy for small organisations to adopt. There may be negative perceptions among small organisations concerning the roles of unions in the Australian construction industry.

\section{Conclusions}

Focusing on safety among small organisations is important to keep improving safety performance in the construction industry because the majority of organisations in the industry are small organisations. Previous research has put forward barriers faced by small organisations to implement safety and has recommended potential strategies to address the barriers. This paper has collected data from the Australian construction industry to identify the key barriers and strategies in this context.

The results show that all the key barriers are external factors, thus small organisations have limited to no control over them. Fierce competition underpinned by lack of safety commitment from the client and the use of lowest bid price to evaluate tender submissions forces small organisations to reduce their costs by any means necessary, including neglecting safety.

Due to the nature of the barriers, the strategies to address them should also involve external stakeholders, particularly the government, clients, and large organisations that actually have the required influence to change the norms and culture of the industry. Practically, these strategies are: including safety as an indicator in tender evaluation, more effective safety enforcement by inspection and linking safety performance with insurance premium and licencing system, and subsidising safety training for small organisations, while also making sure the effectiveness of existing safety training programs.

\section{References}

1. Ozmec, M.N., Karlsen, I.L., Kines, P., Andersen, L.P.S., and Nielsen, K.J., Negotiating Safety Practice in Small Construction Companies, Safety Science, 71(Part C), 2014, pp. 275-281. 
2. Sun, C., An Analysis of Return on Investment on Safety Management Program in Construction Project, Master Thesis, Sydney: The University of New South Wales, 2010.

3. Australian Bureau of Statistics, Counts of Australian Businesses, including Entries and Exits, Australian Bureau of Statistics, Canberra, 2013.

4. Arewa A.O. and Farrell, P., A Review of Compliance with Health and Safety Regulations and Economic Performance in Small and Medium Construction Enterprises, The 28th Annual ARCOM Conference, 3-5 September 2012, Edinburgh, UK, pp. 423-432.

5. Stiles, S., Golightly, D., and Wilson, J.R., Behavioural Safety amongst Construction Industry Supply Chain Contractors, in: M. Anderson (ed.), Contemporary Ergonomics and Human Factors, Taylor \& Francis, 2012, pp. 303-310.

6. EU-OSHA, The Business Case for Safety and Health at Work: Cost-benefit Analyses of Interventions in Small and Medium-sized Enterprises, European Agency for Safety and Health at Work, Luxembourg, 2014.

7. Pybus, R., Safety Management: Strategy \& Practice, Butterworth-Heinemann, 1996.

8. Finneran, A. and Gibb, A., W099 - Safety and Health in Construction Research Roadmap Report for Consultation, CIB Publication 376, CIB General Secretariat, 2013.

9. Lingard, H. and Rowlinson, S., Occupational Health and Safety in Construction Project Management, Oxon: Spon Press, 2005.

10. Legg, S. J., Olsen, K. B., Laird, I. S. and Hasle, P., Managing Safety in Small and Medium Enterprises, Safety Science, 71(Part C), 2015, pp. 189-196.

11. Hasle, P. and Limborg, H.J., A Review of the Literature on Preventive Occupational Health and Safety Activities in Small Enterprises. Industrial Health, 44(1), 2006, pp. 6-12.

12. EU-OSHA, European Agency for Safety and Health at Work - About Us, Retrieved 5 November 2014, from https://osha.europa.eu/en/about, 2014.

13. Zou, P.X.W, Sunindijo, R.Y., and Dainty, A.R.J., A Mixed Methods Research Design for Bridging the Gap between Research and Practice in Construction Safety, Safety Science, 70, 2014, pp. 316-326.

14. Mayhew, C., Quinlan, M., and Ferris, R., The Effects of Subcontracting/outsourcing on Occupational Health and Safety: Survey Evidence from Four Australian Industries, Safety Science, 25(1), 1997, pp. 163-178.

15. Torbica, Z. and Stroh, R., Customer Satisfaction in Home Building, Journal of Construction Engineering and Management, 127(1), 2001, pp. 8286.
16. Mayhew, C. and Quinlan, M., Subcontracting and Occupational Health and Safety in the Residential Building Industry, Industrial Relations Journal, 28(3), 1997, pp. 192-205.

17. Wadick, P., Safety Culture among Subcontractors in the Domestic Housing Construction Industry, Structural Survey, 28(2), 2010, pp. 108-120.

18. Torres, R., Heyman, R., Munoz, S., Apgar, L., Timm, E., Tzintzun, C., Hale, C.R., MckiernanGonzalez, J., Speed, S. and Tang, E., Building Austin, Building Justice: Immigrant Construction Workers, Precarious Labor Regimes and Social Citizenship, Geoforum, 45, 2013, pp. 156156.

19. Zhao, J., Joas, R., Abel, J., Marques, T., and Suikkanen, J., Process Safety Challenges for SMEs in China, Journal of Loss Prevention in the Process Industries, 26(5), 2013, pp. 880-886.

20. Walters, D. and Lamm, F., OHS in Small Organisations: Some Challenges and Ways Forward, The Australian OHS Regulation for the 21st Century Conference, 20-22 July 2013, Gold Coast, Australia.

21. Health and Safety Executive, Costs of Compliance with Health and Safety Regulations in SME's, Research Report 174, HSE Books, Norwich, 2003.

22. Okoye, P.U. and Okolie, K.C., Exploratory Study of the Cost of Health and Safety Performance of Building Contractors in South-East Nigeria, British Journal of Environmental Sciences, 2(1), 2014, pp. 21-33.

23. Jørgensen, K., Duijm, N.J., and Troen, H., Demonstration of Risk Profiling for Promoting Safety in SMEs, International Journal of Workplace Health Management, 4(2), 2011, pp. 179193.

24. Champoux D. and Brun, J.-P., Occupational Health and Safety Management in Small Size Enterprises: An Overview of the Situation and Avenues for Intervention and Research, Safety Science, 41(4), 2003, pp. 301-318.

25. Hasle, P., Bager, B., and Granerud, L., Small Enterprises - Accountants as Occupational Health and Safety Intermediaries, Safety Science, 48(3), 2010, pp. 404-409.

26. Cagno, E., Micheli, G.J.L., and Jacinto, C., Economic Evaluation of OSH and its Way to SMEs: A Constructive Review, Safety Science, 53, 2013, pp. 134-152.

27. Floyde, A., Lawson, G., Shalloe, S., Eastgate, R., and D'Cruz, M., The Design and Implementation of Knowledge Management Systems and E-learning for Improved Occupational Health and Safety in Small to Medium Sized Enterprises, Safety Science, 60, 2013, pp. 69-76. 
28. Lingard, H. and Blismas, N., Client OHS Leadership: An Evaluation of Client Leadership in Occupational Health and Safety in the Australian Construction Industry, RMIT University, Melbourne, 2013.

29. Smallwood, J., Client Influence on Contractor Health and Safety in South Africa, Building Research \& Information, 26(3), 1998, pp. 181-189.

30. Quinlan, M., Flexible Work and Organisational Arrangements - Regulatory Problems and Responses, OHS Regulation for the 21st Century, National Research Centre of Occupational Health and Safety Regulation and National Occupational Health and Safety Commission, Gold Coast, Australia, 2003.

31. Ling, F.Y.Y.L., Liu, M., and Woo, Y.C., Construction Fatalities in Singapore, International Journal of Project Management, 27(7), 2009, pp. 717726.
32. Dulaimi, M.F. and Shan, H.G., The Factors Influencing Bid Mark-up Decisions of Large- and Medium-size Contractors in Singapore, Construction Management and Economics, 20(7), 2002, pp. 601-610.

33. Tam, V.W.Y., Shen, L.Y., and Kong, J.S.Y., Impacts of Multi-layer Chain Subcontracting on Project Management Performance, International Journal of Project Management, 29(1), 2011, pp. 108-116.

34. Votano, S. and Sunindijo, R.Y., Client Safety Roles in Small and Medium Construction Projects in Australia, Journal of Construction Engineering and Management, 140(9), 2014, p. 04014045.

35. Kirkpatrick, D.L. and Kirkpatrick, J.D., Evaluating Training Programs: The Four Levels, $3^{\text {rd }}$ ed., Berrett-Koehler, San Francisco, 2006. 